\title{
CONFERENCIAS
}

\section{ALTERAÇÕES MENTAIS NAS CORÉIAS}

\author{
JULIO PATERNOSTRO *
}

Uma das cenas de "Alice no país das maravilhas" é a seguinte: um gato aparece e desaparece, perturbando Alice, até que ela lhe pede para não voltar mais. O gato vai-se embora lentamente, sumindo primeiro a cauda, depois o corpo e, durante certo tempo, permanecem apenas diante dos olhos esbugalhados de Alice, os esgares do felino. Exclama, então: "já vi gato sem arreganhar, mas arreganho sem gato é uma das coisas mais absurdas de que tive conhecimento!"

Quando neurologistąs e psiquiatras se defrontam, os primeiros olham para os segundos como no caso de Alice. No cérebro, freqüentemente, nada se encontta que justifique as explicações ou interpretações dos psiquiatras sôbre os fenômenos psicopatológicos. Como pode existir "um arreganho" sem gato? dizem então os neurologistas. Neste instante, porém, aceitarão as minhas explicações, pois vou discorrer sôbre alterações mentais com lesões cerebrais.

Olhando-se a cavidade craniana, de cima para baixo, verifica-se que sua arquitetura se divide em três compartimentos ósseos bem diferençados, correspondentes aos três pavimentos ou andares descritos pelos anatomistas: occipital, temporal e frontal. Nesses pavimentos alojam-se os três segmentos da massa encefálica: 1) no andar posterior: bulbo, protuberância anular, cerebelo. 2) no andar médio: núcleo optostriado, lobos occipitais, temporais, da ínsula e hipocampo. 3) no andar anterior: lobo frontal.

Essa divisão tripartida corresponde à distribuição de funções. A Histologia, melhor que a Anatomia, revela-nos certos segmentos regionais do encéfalo, como o lóbulo pré-frontal e o estriado, por exemplo, com estruturas celulares próprias e, portanto, com especialidade de funções. Para avaliar a delicadeza dessas funções e a finura dos comportamentos por ela determinados, basta lembrar que numa grama dessa massa encefálica encerram-se trinta milhões de células ganglionares e trinta mil quilómetros de fibrilas (inclusive o tecido conjuntivo).

Conferência realizada em 14 de novembro de 1943, no Curso de Extensão Universitária de Clínica Neurológica da Faculdade Nacional de Medicina, organizado pelo Dr. A. Austregésilo Filho.

* Assistente do Ambulatório de Neuro-Sífilis da Fundação GaffréeGuinle - Rio de Janeiro. 
No bulbo, na protuberância, no cerebelo encontram-se as principais funções do instinto, isto é, a tendência para a conservação individual e propagação da espécie. Circulação, respiração, digestão, reprodução, equilíbrio e controle dos movimentos involuntários constituem elementos da vida instintiva, cujos centros estão no cérebro posterior. No cérebro central se elaboram e se condensam as emoções. A dor, o pavor, o chôro, a cólera, o rìso, a alegria, as nossas paixões, o nosso entusiasmo pela beleza, enfim êsses fenômenos complexos da vida sentimental que formam o tempenamento têm, no tálamo e terceiro ventrículo com especialidade, o seu centro. E o segmento da afetividade. No lobo frontal realiza-se a síntese das funções que caraterizam a inteligência.

Mas o mecanismo do encéfalo, a engrenagem de suas funçōes desde as mais superficiais às mais ocultas, não respeita aquela divisão tripartida, diante das exuberantes vias de comunicaçõess que entrelaçam os segmentos. Estes não trabalham separadamente, mas em bloco, e essa unidade funcional do encéfalo jamais deve ser esquecida ao tratarmos das afecções dos núcleos da base.

Sabe-se que a sensibilidade e a motricidade de nosso corpo têm sua representação total ao comprido das duas circunvoluções que margeiam a cisura de Rolando e que essa representação se distribui, de acôrdo com um velho símbolo, como se fôsse um homem que tivesse a cabeça voltada para o lago silviano e as pernas para a circunvolução paracentral.

O espaço ocupado pela sensibilidade na cortiça cerebral não está em proporção com a extensão da superfície corporal que representa, mas sim com o número de neurônios que a determinada região contém. A polpa dos dedos, por exemplo, embora possua uma superfície muito menor que a da. espádua, tem uma localização cerebral muito maior, devido precisamente à riqueza extraordinária de seus receptores sensoriais. $\mathrm{Da}$ mesma forma $\mathrm{e}$ pelos mesmos motivos, a extensão das localizações motoras não está em proporção com o tamanho ou o número dos músculos, mas com a riqueza de sua inervação. A musculatura do tronco, por exemplo, ocupa um lugar mínimo na cortiça cerebral, enquanto que o polegar e o índice exigem, só para èles, uma superfície considerável, quase do tamanho da que corresponde à perna. A complexidade e o valor psíquico dos movimentos determinam a maior ou menor extensão de localização na cortiça. Depreende-se daí que essa maior extensão, pelo simples fato de ser maior, se torna mais fàcilmente atingivel, quando os processos mórbidos se instalam no encéfalo.

A mão, "êsse cérebro externo do homem", segundo o feliz paradoxo de Kant, merece algumas considerações, pois ela traduz em movimentos especiais (como os coréicos, os atetóticos, os de enrolar pílulas dos parkinsonianos), várias enfermidades do sistema extrapiramiradal.

A aptidão para formar uma pinça com o polegar e o índice, de enorme importância no comportamento da mão, aparece após q̀uarenta semanas do nascimento. Depois dos quatorze meses ela deixa de ser um elemento provisório da função de locomoção, para se tornar no melhor e mais útil instrumento de conquista da realidade. Mais que a vista e o ouvido, a mão ensina à criança conhecer os objetos e detalhar suas partes. Nada como "apalpar as coisas", dizemos nós adultos, quando queremos sentir a realidade. Sem a mão, os cegos não se instruiriam, "não enxergarian".

Longe de ser uma função elementar e primitiva, como descrevem os manuais, o tacto é o produto de uma laboriosa e profunda análise. Permite penetrar no interior das coisas, enquanto a vista, por exemplo, se detém quase sempre na superfície do objeto. A vara que se introduz na água jura aos olhos que está quebrada; a mão nos ensina a ser prudentes. Ai de nos- 
sos colegas cirurgiões, apesar da técnica maravilhosa dos raios $\mathrm{X}$, se não fossem as mãos que controlam os segredos do abdome, mal aberto por uma pequena incisão!

O olfato, o gôsto, a visão e o ouvido contribuem para a elaboração das funções mentais superiores, com as formas de conjunto ou a chamada "percepção sincrética” de Renan ou a "Gestaltqualität" da atual escola de Kohler, mas a mão, na verdade, é que precisa os contornos e controla a realidade. Dela depende o problema social da "habilidade manual" tão importante para a seleção profissional e os testes de psicotécnica.

Os modernos estudos de anatomia cerebral localizam no estriado o centro da "habilidade manual". Mas, em vez de se admitir, como antigamente, que as contrações inúteis e descontroladas eram apenas uma insuficiência dêsse órgão, hoje, graças aos estudos de Monakow e von Economo, sabe-se que elas estão diretamente subordinadas à influência da cortiça cerebral.

As relações do estriado e cortiça, as funções centrífugas e centrípetas devem ser consideradas, quando observamos os doentes do sistema extrapiramidal. Um coréico ou um parkinsoniano, com mãos que não controlam a realidade, têm, como sobrecarga aos distúrbios da cortiça alterada, falsas e insuficientes percepções sincréticas que mais ainda perturbam o funcionamento da atividade inteligente.

Quando falamos em localização cerebral das faculdades mentais, é claro que não pretendemos apontar com a vareta, no esquema do cérebro, o local da consciência ou da vontade. A consciência da mão, por exemplo, não está localizada, mas sim os seus componentes psíquicos, isto é, as memórias ou engramas dos seus movimentos que concorrem, com tôdas as outras memórias, à elaboração da consciência. A mesma coisa se dá com a vontade ou a inteligência, resultados finais de um vasto trabalho cerebral.

Cada território sensorial parece que se compõe de duas partes, uma das quais prepara o material que serve à outra. A primeira chama-se sensorial, a segunda psicossensorial; esta funciona normalmente quando a outra a excita, ou então quando a zona que a precedeu no desenvolvimento está perfeitamente integra ou, ainda, quando não está alterada por um processo patológico.

A relação que já assinalamos entre o estriado e a cortiça se reproduz para cada zona cerebral dos sentidos. Quando os órgãos de orłem inferior suspendem o seu trabalho, as funções perceptivas do centro psicossensorial se detêm, privadas que ficam dos materiais, embora se achem em perfeitas condições. Estamos fartos de ouvir ou de ver que os coréicos dormem tranqüilamente, e eu, nos poucos casos que estou observando, tenho indagado a respeito dos seus sonhos. Até hoje não consegui, inclusive num paciente médico, portanto com conhecimentos superiores para entender o que eu desejava, reprodução de sonhos partindo de estímulos sensoriais externos. Isto está me induzindo a pensar, embora seja prematura qualquer afirmação, que grande parte da redução funcional do cérebro nessas molestias, seja devida à falta de preparação do material para a parte psicossensorial, pois, como se verifica, a visão, o olfato, o gôsto e a audição conservam-se íntegros, de um modo geral, nesses doentes.

O despertar da imagem acústica da palavra "pena”, por exemplo, está subordinada à presença das imagens visuais e tácteis da pena. Se estas falham, embora o objeto esteja diante do examinado, a imagem verbal acústica que a simboliza não será evocada ou então tomará um caminho indireto depois de certo tempo. Assim, por exemplo, a uma coréica à qual mostramos um dêsses distintivos que andam na lapela de muitos, "o fole" - ela res- 
pondeu-nos "onde se sopra com o ar". Embora esperássemos por meia hora, não houve meio de chamá-lo de "fole".

Não se devem considerar as localizações no sentido concreto e vulgar, mas no de uma série indissolúvel de processos, cada un dos quais tem seu órgão específico, estreitamente unidos sob o ponto de vista funcional. Isoladamente, os elementos sensoriais não constroem a imagem concreta das coisas. Para isto, êles precisam estar coordenados. Formadas as percepções simples, atuais ou representativas, elas se coordenam por sua vez e, segundo as leis da associação, originam produtos mais complexos. A produção intelectual, as vivências vão se engatando, multiplicando-se até atíngir as concepções abstratas, que são novos pontos de partida para outras coordenações. $\mathrm{E}$ a sucessão de vastas coordenações atinge o seu mais alto grau no que denominamos o "pensamento criador", isto é, o tipo de pensar que gera o conhecimento, o qual nos leva a encarar as coisas de maneira diversa da anterior e age na sua reconstrução.

Onde se realizam essas vastas associações, essas delicadíssimas coordenações dos produtos sensoriais que criam as concepções complexas traduzidas pela conduta? Não receamos responder: nos lobos frontais. Nas várias camadas das células piramidais se encontram os territórios da linguagem, que se devem distinguir da área anatômica da palavra. A palavra pode sofrer perturbações não sòmente quando os órgăos intrínsecos de seu mecanismo foram atingidos (como no caso de pacientes de afeç̧ões do sistema extrapiramidal - palavra disártrica, escandida), como também quando se perturbam os mecanismos que elaboram o conteúdo mental (imagens concretas e idéias abstratas) e, ainda, quando se interrompem as vias que unem os campos das imagens e das noções que tornam possível o processo lógico.

A incapacidade de encontrar as palavras adequadas aos objetos e a sua substituição por outras de significado diverso, a tendência à perseveração que encontramos nos coréicos de Huntington, são exemplos categóricos dêste caso.

Pode-se considerar a linguagem como a síntese da inteligência, pois é ela que transforma em símbolos as emoções, os sentimentos, a conduta e estados representativos. Quando suas áreas cerebrais são atingidas pelo processo mórbido, todo o patrimônio mental do indivíduo se desmantela. Não importa que as zonas sensoriais continuem funcionando, o material por elas recolhido não é mais utilizado, porque não só faltam símbolos, como o mecanismo da formulação dos juízos complexos em séries lógicas se interrompe. Num grau incompleto é a afasia. Num grau completo, a demència ou o estado definitivo e irremovível a que chegam os doentes, na última etapa dos processos mórbidos degenerativos.

Subimos, com esta síntese, os três andares da cavidade craniana, onde vivem o instinto, a afetividade e a inteligência. Bons vizinhos quando há harmonia entre êles; maus, desastrosos parceiros quando ela se rompe. No último andar, os lobos frontais governam a conduta pelas inibições. E, como encerram as funções nuais delicadas e complexas, não deixam de sofrer as conseqüências de alterações que se passam nos pavimentos inferiores. Funcionam quase sempre como sismógrafos dos terremotos que começam a se instalar nos cérebros central e inferior.

A equipe de escol que me precedeu neste lugar já se referiu à anatomia, histologia e fisiologia patológicas e às afeç̧ões do sistema extrapiramidal. Já sabem, portanto, quais os territórios cerebrais atingidos e os quadros clínicos que êles apresentam.

Os sintomas mentais que decorrem daquelas modificações histofisiológicas e que se sobreajuntam aos orgânicos, podem ser agudos ou crônicos. Para melhor facilidade descritiva escolhi dois tipos de afecções: uma aguda, 


\section{infecciosa, a Coréia de Sydenham; outra crônica, degenerativa, a Coréia de Huntington.}

O seguinte caso clínico dá uma idéia das alterações mentais numa doença aguda do sistema extrapiramidal.

C. M., sexo feminino, 14 anos, branca, residente nesta cidade. Essa mocinha adoeceu em novembro do ano passado e esteve sob meus cuidados profissionais de 20 de abril a 15 de agôsto dêste ano.

Filha primogênita de pais brasileiros, da classe média. Tem dois irmãos menores sadios. $O$ pai morreu aos 48 anos, de doença pulmonar, quando Creusa tinha 12 anos. A mãe, com quem mantive contacto durante a doença da filha, é sadia, calma, segura de seus atos, ativa. De estrutura corporal picnica, ao contrário de seu falecido espôso, cuja fotografia revelou-me um tipo de tendência leptossômica. A filha herdou esta estrutura. A māe teve abortos, seus exames de sangue foram sempre negativos e disse-me que, em sua família, só um tio sofreu de doença mental, o qual passou alguns anos internado num Sanatório. Quanto aos parentes do espôso, lembra-se de uma irmã dêste, já falecida, que sofria de ataques epiléticos. Não co'hi outros dados sôbre antecedentes psicopáticos da família da paciente.

Creusa nasceu após gestação e parto normais. Aos 6 meses, sob regime alimentar artificial, teve impetigo generalizado. Passou bem do $1 .^{\circ}$ ao $4 .^{\circ}$ ano de vida. Com quatro anos contraiu sarampo e, em seguida, impetigo e um antraz no psecoço que a debilitaram muito. Nessa casião, durante um mès apresentou várias "poussés" de temperatura. Banhos e fortificantes fizeram a menina recuperar a saúde $e$, aos 7 anos, matriculou-se na escola. $O$ aprendizado escolar primário se fêz normalmente, tendo perdido um ano, devido a uma doença intestina1, cuja etiologia não consegui apurar.

AOs 12 anos terminou o curso, justamente quando seu pai faleceu. Suas regras apareceram em 4 de setembro de 1942, aos 13 anos completos e compareceram regularmente até 1.0 de janeiro dêste ano, quando se interromperam. Até setembro déste ano permaneceu amenorréica, isto é, durante o período da doença à qual atendi.

Quando a vi pela primeira vez, limitou-se a responder poucas perguntas. Calada, sentou-se na cadeira e assumiu uma atitude negativista, embora me olhasse de soslaio, com certa expressão de môfa. A única frase foi: "não me compreendem".

Contou-me a māe o seguinte: Creusa era muito agarrada ao pai e chorou muito a sua morte, tornando-se, há pouco mais de um ano, irritadiça, "nervosa", com tendência a se isolar e rir à toa. Dá gargalhadas sem motivo, na rua ou no cinema, falando alto e fazendo caretas para os estranhos. Cuidadosa até entāo no vestir-se, tornou-se desmazelada. Freqüentemente a mãe era obrigada a chamar-lhe atenção para abotoar o vestido e pentear o cabelo, emborá se demorasse muito tempo diante do espêlho. Ûltimamerte, a mãe não a compreendia: ora ela estava muito alegre, exagerada no falar, ora se entristecia e permanecia muda. Tornara-se ảesastrada, "quebrando muita louça", "deixando as torneiras abertas". Não há anormalidade quanto ao sôno. Recentemente brigava muito com os irmãos, e destruia os seus brinquedos.

Estava se preparando para o exame de admissão ao ginásio, mas, como nas aulas tornara-se turbulenta e não "prestava atenção", tirando más notas, a mãe, que recebia queixas freqüentes do diretor, reso!veu tirá-la do colég.o, dizendo-lhe que "como castigo não a manària mais para o estudo, e que, afinal de contas, ela serviria para lavadeira". A mãe falara "lavadeira" como podia dizer "cozinheira", mas o interessante é que a mocinha, tomando a peito a admoestação materna, resolveu "lavar as roupas de casa", coisa que nunca fizerá, até então. Há seis meses não ia à escola, saía freqüentemente de casa e procurava estar só na companhia de rapazes, fato que, de uma feita, mereceu acerba recriminação da mãe. Isto aumentou extraordinàriamente $a$ hostilidade entre ambas. $O$ resultado do exame do líquor apenas revelou uma discreta pleocitose: 3 cels. por mm. ${ }^{2}$; albuminose de 0,30 . Confesso, não atinei com êsse resultado. As reações sorológicas da sífilis foram negativas.

Fiquei sem diagnóstico definitivo. Admiti, à primeira vista, devido à etapa endocrínica por que ela estava passando, e à alteraçāo do lar conseqüente à morte do pai, o qual a mimava, $\mathrm{cm}$ contraste com a mãe, que se inclinava para os outros dois filhos, tratar-se de um caso de disendocrinia e desajustamento familial. Mas, ao mesmo tempo, certos sintomas - desleixo na vestir, dificuldade em se abotoar e se pentear, permanência longa diante do espêlho alterações acentuadas da conduta, advertiam-me prudência.

Numa ocasião, teve uma conduta que podemos chamar de "lasciva". Apertou demasiadamente minha mäo e perguntou-me porque não tirava a aliança do meu dedo, acompanhando essa pergunta de um. piscar de olhos. Nesse dia levava freqüentemente as máos aos órgãos genitais e levantou o vestido bem acima dos joelhos. Noutra ocasião, percebi que seus dedos se moviam como se estivessem "farejando" os objetos. Eram movimentos discretos, mas anormais, desordenados, involuntários e suas māos estavam exageradamente suadas. Chamando-lhe a atenção para êste último fato, ela respondeu-me: " $E$ verdade, doutor, de uns dias para cá minhas mãos não param de suar", mas nada referiu sôbre os movimentos anormais. Entretanto, o exame neurológico - marcha, postura, reflexos - foi negativo. Uma semana após aquela observação de suas mãos, irromperam os movimentos coréicos, tomando conta dos gestos e do andar da paciente. Tratada pelo método de Balena, já retomou suas atividades escolares. 
Destaco, então, como sinais premonitórios: distúrbios da conduta e do instinto; enfraquecimento das propriedades inibitórias do lobo frontal. Durante a manifestação neuro!ógica da doença notamos: ligeiros distúrbios da atençāo (verificados pela prova de Bourdon) e certa irritabilidade do humor, manifestada principalmente na presença da māe. Prova evidente das relações psicológicas complexas, isto é, das áreas especializadas da cortiça com os cérebros central e posterior.

A associação de idéias tambem se tornou lenta. E claro que evitamos qualquer teste escrito, para não entrar em jôgo o fator emocional diante das dificuldades impostas pelos movimentos coréicos. As perguntas simples de geografia, capitais de países, de estados, demorou em responder, e, outras vezes, disse-me que não sabia. Mas, depois do restabelecimento, as mesmas perguntas tiveram respostas certas e prontas. Não houve alterações da memória, mas as inibições desde a fase pré-neurológica foram evidentes. Inicialmente não dei atenção ao líquor, porém, depois, lembrei-me que nesses casos costuma haver albuminose e linfocitose discretas.

Na sua familia não houve casos de coréia. E uma paciente de sistema nervoso frágil, e o impetigo rebelde que, desde os primeiros dias de vida se manifestou, induz-me a classificá-la como de fraca resistência às infecçôes. Um fato que náo devo deixar de salientar entre os fatores desencadeantes dessa enfermidade aguda, é o choque emocional. A paciente, segundo informação de sua mãe, principiou a adoecer após a morte do pai. Este tinha especiałmente para ela um valor especial; na família, foi quem mais a cumulou de carinhos.

Referí-me, linhas atrás, ao assunto de seleção do pessoal. Citarei de passagem um caso observado por mim que se relaciona com a Medicina do Trabalho. Embora, pràticamente, no nosso país a interferência do psicólogo e psiquiatra nessas questões ainda seja insignificante ou nula, nós clínicos devemos, pelo menos por solidariedade humana, contribuir para que os pacientes não sejam prejudicados, em seus direitos de trabalhadores.

V., parda, 16 anos, fisicamente bem constituida. Trabalhava numa pequena fábrica de caixas de papelão. Seu mister consistia, há dois anos, em passar cola em papéis. Ganhava como tarefeira.

Em novembro ú'timo principiou a reduzir sua produção e esperdiçar cola, fato que, além de diminuir seu salário, serviu de base para admoestações do patrão e de um seu irmão mais velho. Fste achava que V. se tornara vadia, devido ao namóro que mantinha com um rapax. A moça tornou-se irritada, malquista pelas companheiras de trabalho, porque não dava "vencimento" (sic), isto é, as prejudicava no serviço. Tais serviços, como sabłem, são taylorizados. Cada operária completa a parte da outra, de modo que V. foi considerada como "mau clemento". V. está hoje se tratando de coréia, com injeçóes de salicilato de sódio. Seu prejuízo no trabalho foi conseqüência da doença que estava se instalando.

Os movimentos anormais das mãos conseqüentes a doença infecciosa do sistema nervoso trazem, pois, complicações psicológicas, e devo lembrar que estas, por sua vez, influem desastrosamente na destreza. Quero dizer que, quando nos relatam uma história de falta de habilidade manual, não devemos admitir desde logo a existência de sintôma prodrômico de u'a moléstia do sistema extrapiramidal, pois, freqüentemente, estados emocionais crônicos, desajustamentos de ambientes familial e social alteram a destreza.

Analisemos agora os sintomas mentais da doença degenerativa: a Coréia de Huntington. Trata-se de u'a moléstia que aparece na idade adulta ou senil, de transmissão hereditária direta e homomorfa e com distúrbios mentais progressivos.

As seguintes observações de Meggendorfer oferecem-nos um quadro expressivo das alterações mentais na Coréia de Huntington:

Caso 1 - Max Kramer, operário. Foi bom aluno. Aos 35 anos trabalhava como confeiteiro quando, perdendo as sensações gustativa e olfativa, abandonou essa profissão. Casara-se 5 anos antes, e empregou-se num estaleiro, onde se tornou conhecido como um homem muito nervoso e fàcilmente irritável. Contraiu pneumonia $e$, pau?atinamente, instalaram-se os sintcmas da Coréia de Huntington, que lhe impediu de ganhar a subsistência e o fêz perambular pelos hospícios pelo resto de sua vida.

Sua linguagem é confusa, penosa. Suas frases são constantemente interrompidas pelos movimentos da cabeça. Só por muito pouco tempo, consegue, pe'a vontade, impedir os movimentos. Durante o sôno torna-se tranqüilo. L lúcido, tem consciência da moléstia, sabe que sua māe e sua tia sofriam do mesmo mal e que jamais recuperará a saúde. Percehe tambénı que não pode fixar conhecimentos novos. A associação de idéias é lenta; queixa-se de que 
- taquitoscópio é muito rápido. Na execução da prova de Bourdon, demora e falha muito. Só faz cálculos com algarismos abaixo de 10. Associa as idéias de modo peculiar, por exemplo: tempestade: "campanha"; pigmeu: "pomba pigméia"; assassino: "companheiro". Na representação de idéias designa, sem sentido algum, de "provisórios": sapateiros, alfaiates, marceneiros, serralheiros, túnel, casa, igreja, tôrre e ponte. Lê um trecho mutilado, sem perceber que faltam palavras. Os ccnhecimentos escolares acham-se defeituosos; diz, por exemplo, que "a ave é um mamífero" e "a borboleta um anfíbio". Quanto às côres, demora muito para designá-las. Freqüentemente, quando se the mostra um objeto, responde "não sei". Outras vezes reconhece o objeto, mas nāo lhe dando o nome exato, faz rodeios para designá-lo. Por exemplo, punho é "mão fechada", bússo'a é "mostrador de este, œeste, sul e norte" (o doente trabalhou durante alguns anos como confeiteiro de bordo). Aranha é ora "piôlho", ora "môsca".

Realiza sem dificuldade os atos simples da vida cotidiana e também sabe cumprimentar militarmente, ameaçar os otutros. Antes, era bom pai de família. Recebe as visitas de seus parentes com sentimentalismo. Geralmente, se isola dos companheiros de intẹrnaçāo, aparentando ser um indivíduo que não se interessa pelos fatos do seu pequeno múndo, exceto para comer. Come brutalmente, mantendo assim um certo pèso corporal. O seu armário é uma gaveta de sapateiro: nela se encontram, misturados, alimentos, papel, tabaco. Completamente desarranjado no vestir, sujo. Anda sempre atrasado: é o último a se levantar pela manhã, o último a se deitar à noite. Para ser examinado é preciso que o arrastem à sala do médico. Nenhum doente quer ser seu vizinho na mesa, pois suja tudo, come muito devagar e é estabanado, devido naturalmente à inquietude motora.

O paciente tem consciência de sua incapacidade, de suas falhas. As vezes, ainda não lhe perguntamos nada e responde de antemão: "isso é muito difícil para mim", "sou fraco no cálculo", e, quanto à sua história anterior, costuma repetir, sem nos dar atenção às perguntas: "disso sabe minha espôsa". E cheio de suscetibilidades, julga-se constantemente ofendido. Se outro doente o olha casualmente, logo admite que o está provocando. Se o servente prepara - banho para um doente antes do dêle, queixa-se amargamente e isso não sai de seu pensamento durante semanas, nāo havendo razōes que o tranqüilizem. Quando denuncia essas coisas, se excita extraordinàriamente $e$ atinge a uma tal tempestade de movimentos, que não pode mais falar. $O$ interêsse pela sua família, porém, é constante. Sai com licença, várias vezes, viaja sòzinho, de trem e a pé, para as visitas domésticas e volta sempre no dia marcado.

Caso 2 - Teodoro Welten foi um comerciante inteligente e hábil. Era muito sociável, alegre. Vivia numa boa roda de amigos, embora se tornasse, às vezes, "nervoso", colérico, estrilando por um nāo-nada, mas não guardava ressentimentos.

Como progredisse numa cidade do interior, vendeu bem a sua casa de negócio e instalou-se em Hamburgo. Aqui, a sua vida de comerciante não foi feliz. Aceitou entāo um lugar de contador numa firma. Traba!hava muito e, aos 46 anos, aquelas crises anteriores de cólera, tornaram-se quase diárias. Numa noite, agitou-se sem motivo no leito, rasgou os lençóis e depois dormiu. Começou então a andar vacilando e muitos o supunham embriagado. A moléstia desenvolveu-se ràpidamente. Os movimentos involuntários, as excitações psíquicas assumiram grandes proporçōes. $\mathrm{Em}$ casa, começou a quebrar cadeiras, rasgou as cortinas, agrediu, quase estrangulando a espossa e, pulando uma janela, saiu de cuecas na rua gritando que "queriam matá-lo". Foi internado num hospício.

Exceto a inquietação motora, seu organismo é normal. A linguagem é lenta, monótona, am ú. e incompreensivel. Psicològicamente, porém, é lúcido, sabe que sua doença é incurável. Năo encontra palavras para nomear certas coisas; um morcègo é "um bicho que von de noite", uma cobra é "um animal venenoso da floresta", etc. A associação de idéias oferece um modo peculiar de reação. Assim: veneno - para matar; quilo - para pesar; mêdo - no corpo; ladrāo - na prisāo; cisne - na água, etc. São reações fixadas.

Sua memória de fatos anteriores à doença é perféta. Guarda relativamente bem seus conhecimentos escolares. Pelo exame dos conceitos abstratos, também, certo grau de conservação, embora, às vezes, não os diferencie; assim, "êrro" e "mentira" são mais ou menos a mesma coisa. Não alcança o sentido de provérbios comuns, não entende historietas singelas, descritas numa série de fotorafias.

Welten se isola dos outros doentes, lè por acaso algumas revistas e freqüentemsnte estende a vista para um horizonte imaginário, como se estivesse sonhando acordado.

Suscetivel, admite que os outros doentes vivem a mangar dêle. Se o contrariam num desejo fútil, encoleriza-se, lança desordenadamente seus membros corécos para os lados, agarra as pessoas vizinhas, grita, chora. Nos periodos de calma é bem visto pelos seus companheiros de hospital. Faz esforços para se manter bem composto, limpo e mantém seus objetos em ordem.

Casa 3 - G. Buhl, lavrador. Sadio até a idade de 44 anos, quando recebeu a notícia da morte de seu filho na guerra de 1914. Surgiram-lhe movimentos involuntários no corpo, sabeça e membros e a linguagem tornou-se incompreensível. Devido às agressões repetidas à sua espôsa, foi reco'hido ao Hospício. 
Foi demonstrada, a'ém da corëa, a presença de sifilis. Após o tratamento pelo neo salvarsan, o doente, melhorado, recolheu-se a casa. Pouco tempo permaneceu, porém, fora do Hospital, devido às reações anti-sociais.

Sua fala é lenta, pesada, dificilmente compreensivel, como se tivesse um objeto na bôca. A intensidade da acentuação e a tonalidade das silabas variam sem motivo.

O paciente está orientado no tempo, lugar e meio. Tem consciência da doença, sabe que sofrc de moléstia hereditária, que nấo se curará. Designa erradamente os objetos que lhe são mostrados; outras vezes, porém, acerta. Corrige as falhas de orientação. A associação de idéias é lenta. A verbigeração é freqüente. Fixa as representações visuais, mas não as acústicas. Recorda e dá o s'gnificado de algumas datas nacionais, acredita que "o morcêgo é uma ave", que "a baleia é um peixe", etc. Opera regularmente com as quatro operações. Não entende as anedotas, as historietas; não dá por falta das mutilaçōes de trechos que lhe são apresentados para ler.

Quanto à vida emocional, Buhl vive aflito, de mau humor. Anda só, nāo conversa com og outros pacientes. Diante dos méd cos queixa-se sempre que a comida é insuficiente, embora tenha uma ração maior que os seus companheiros. Quer sair, agita-se quando lhe respond $m$ negativamente e, de uma feita, fugiu do Hospital, indo parar em sua casa. Depois dessu fuga passou um longo período calmo e os enfermeiros cons deram-no como um dos doentes mais dóceis.

Não reproduzimos outras observações porque, em linhas gerais, coincidem com as já referidas. Os distúrbios mentais podem ser assim catalogados, de um modo resumido:

1 - Perturbaçóes agnósticas, apráxicas e afásicas. Agnósias do olfato e do paladar: os doentes sentem, por exemplo, cheiro de poeira em todos os objetos; a comida ora está salgada, ora doce, etc. As perturbações afásicas talvez derivem das dificuldades gnóticas da visão, da tendência à perseveração, isto é, responder às perguntas com as mesmas palavras. Elas caraterizam-se sobretudo pela dificuldade na procura das palavras. Os doentes reconhecem os objetos, mas não os designam. Fixam-se numa impressão secundária da pergunta. Tornam-se circunstanciais, gesticuladores, pois êles mesmos se dão conta dos erros. Lembram os casos de afasia amnéstica de Pitres. Há uma ligação defeituosa dos centros de identificação com os das imagens sonoras das palavras. Além da disartria, o restante das funções verbais dos doentes é bem conservado. As perturbações apráxicas são difíceis de ser evidenciadas nos coréicos, devido aos distúrbios motores existentes. São instáveis: ora as encontramos, ora não. Os doentes exercem todas as atividades da vida cotidiana: acendem a luz, cumprimentam, acendem cigarros, etc.. As vezes, porém, os movimentos coréicos impedem-nos nessas tarefas simples. Não aprendem novas tarefas, embora sejam mais elementares que as executadas antes da moléstia.

2 - $A$ atenção é oscilante e o principal defeito se nota quanto à concentração. Devido aos movimentos exagerados, a excitação dos estímulos externos é grande. A hipervigilância e a hipotenacidade decorrem das inúmeras sensações tácteis, representações óticas, acústicas e outras representações secundárias, que impedem a permanência no campo mental da representação principal e desejada. A perturbação motora distrai perpètuamente a atenção; a dificuldade de ligação dos elementos intelectuais reduz mais ainda a concentração da atenção.

3 - $O$ curso do pensamento torna-se permanentemente interrompido e retardado devido à perturbação motora; elementos estranhos intervêm nas ligações. A perseveração formal é freqüente. Os pacientes repetem quasi estereotipadamente as mesmas reaçôes ou a mesma espécie de reação. Quando lhes perguntamos qualquer coisa, ficam, às vezes, como que coagidos a responder frases, versos, aprendidos numa fase anterior à doença. $O$ diálogo com êles assume então uma feição disparatada. Truísmos e repetiçôes das mesmas conversas são comuns. A associação de idéias é lenta. Apesar da inquietação motora, a mímica, que tem tanta conexão com o pensar, asse- 
melha-se à dos parkinsonianos. Entre tantos movimentos, a mímica é rígida. E isto, provàvelmente, deve-se às perturbações associativas, ao retardamento, à dificuldade das sínteses psíquicas.

4 - A memória é relativamente bem conservada. Os autores embaralham muito êsse particular. Confabulação, falsificações, se existem, não sei. Até o presente, não encontrei referências sôbre essas alterações da memória nos coréicos. As vezes, falham completamente na recordação de conhecimentos escolares os mais simples, mas, noutras, emitem conceitos elevados sôbre as coisas que aprenderam. Com o progresso da moléstia, a capacidade de fixação se reduz em conseqüência dos movimentos coréicos e da "perturbação disposicional" (exuberância das representações secundárias em relação com o atraso da ligação das ocorrências perceptivas e verificativas). $O$ estreitamento paulatino do patrimônio intelectual, apesar da conservação relativamente boa da memória, é infalível. Compreende-se fàcilmente que o atraso e a inibição das ligações, a perturbação disposicional freiam-lhes a mobilidade do espírito, a imaginação, que constituem, nos indivíduos sadios, um estímulo para o enriquecimento intelectual. Assim, não é raro que os observadores, diante dos coréicos de Huntington, recordem-se dos epiléticos e dos oligofrênicos.

5 - O juízo crítico varia muito, mas é decisivo, neste caso, o tempo de doença. No fim, se apaga. As idéias obsessivas, nos casos puros de Coréia, não desempenham um papel importante. No início da moléstia, às vezes, surgem idéias depressivas, de perseguição e, no fim, desenvolvem-se idéias de grandeza e eufóricas. Não há, entretanto, uma sistematização desenvolvida dessas idéias. E possível que as idéias obsessivas dos coréiços tenham a mesma gênese que as fantasias dos surdos, velhos e prisioneiros. Desamparados como êstes, os coréicos tornam-se desconfiados, relacionam os gestos e os sorrisos dos outros à sua pessoa. Quando confiam no ambiente, geralmente as obsessões desaparecem.

6 - As aluciną̧ões não desempenham papel importante nos coréicos. Existem mais recordações que, devido à insuficiência do aparêlho perceptivo, dão a aparência de alucinações.

7 - A emotividade sofre mudanças paulatinas no curso da moléstia. Anos antes da moléstia se declarar, os coréicos de Huntington são classificados como personalidades psicopáticas, esquizofrênicos e até paralíticos-gerais, devido à ansiedade, explosões, cóleras, alterações da conduta, impulsividade, certa rigidez afetiva e tonalidades afetivas depressivas e expansivas, que thes alteram freqüentemente o humor. Os coréicos tèm consciência da doença; falta-lhes, porém, o próprio sentimento mórbido. A maioria sabe que não se cura, tem sentimentos de desamparo e de inferioridade que os fazem se afastar do meio e então respondem-nos falsamente às perguntas, dando-nos a impressão de imbecis. Conservam grande interêsse pela comida. Comem, devorain com uma fome insaciável. E a maioria vegeta seus últimos dias nos Hospitais, como plantas açoitadas irregularmente pelos movimentos desordenados.

Conforme a análise psicológica e clínica que fizemos das alteraçõę mentais nas Coréias, a sua localízação se estabelece em duas regiōes cerebrais: estriado e cortiça cerebral.

Podemos afirmar: não há, geralmente, coréicos sem perturbações mentais. Isto significa que a moléstia não é só do estriado, pois os distúríbios meta-encefálicos não explicariam jamais toda a riqueza de sintomas mentais que descrevemos

A clínica se ajusta, neste caso, perfeitamente, às investigações histopatológicas dos últimos anos, de Kieselbach, Ruske, Stern, C. e O. Vogt, Jakob 
e Spatz, que interpretam a Coréia de Huntington como um processo degenerativo do estriado e da cortiça cerebral. Jakob e Spatz evidenciaram, além disso, a acentuada coincidência entre a estrutura anatômica do estriado $\mathrm{e}$ das três camadas inferiores da cortiça cerebral, constituindo, ambas as partes, um íntimo complexo genético.

A Coréia de Huntington é uma doença dos centros sistemàticamente juntos, isto é, do estriado e das camadas corticais inferiores, por isso suas manifestações clínicas são inseparáveis, quer do psiquismo como da motilidade.

Ficamos, portanto, psiquiatras e neurologistas, bem entendidos nesta moléstia, pois, como disse no coméço, temos "os arreganhos e o gato".

R. Neves, 1 - Rio de Janciro. 